\title{
Optimal Placement and Sizing of TCSC: A Meta-Heuristic Multi- Objective Approach
}

\author{
Pawan Chandrakant Tapre \\ HOD(Electrical) \& Assistant Professor, \\ SND College of Engineering \& Research Centre, Yeola, India \\ pawanchandrakant.tapre25@gmail.com
}

\begin{abstract}
In the deregulated power systems, the optimal placement of TCSCs is a solution for enhancing the power system's stability. The TCSC is the first series of a FACTS device and it is good in compensating the reactance of the transmission line, and thereby increases the power flow via the transmission line. In this research work, the optimal placement and sizing of TCSC is achieved with the aid of an optimization algorithm referred as MPU-WWO, which is the conceptual improvement of standard WWO algorithm. Then, to achieve the optimal placement of TCSC, the objectives such as, "minimizing the congestion, reducing the reducing the investment cost and increasing the transient stability" are considered. The proposed optimal location and sizing of TCSC is tested in "IEEE 24 test bus system and the IEEE 9 test bus system" in terms of investment cost, Congestion cost as well. When the count of TCSC $=3$, the lowest congestion cost is recorded as 500(\$) by the proposed work with MPU-WWO, while the proposed work with PSO, ABC, GWO, DA and WOA records the congestion cost as $530(\$), 510(\$), 555(\$), 510(\$)$ and 554.74(\$).
\end{abstract}

Keywords: Optimal Placement; TCSC; Congestion Management; Transient Stability; IEEE test bus system; MPU-WWO.

\begin{tabular}{ll} 
Nomenclature & \\
\hline Abbreviations & Descriptions \\
\hline ABC & Artificial Bee Colony \\
ATC & Available Transfer Capability \\
DA & Dragonfly Algorithm \\
GWO & Grey Wolf Optimization \\
IMFO & Improved Moth Flame Optimization \\
JMFO & JAYA Blended Moth Flame Optimization \\
MPU-WWO & Modified Propagation Update Based WWO \\
OPF & Optimal Power Flow \\
PSO & Particle Swarm Optimization \\
SVC & Static VAR Compensator \\
TCSC & Thyristor Controlled Series Compensators \\
TCR & Thyristor Controlled Reactor \\
WOA & Whale Optimization Algorithm \\
WWO & Water Wave Optimization \\
\hline
\end{tabular}

\section{Introduction}

The electricity sector is facing a dynamic change that has paved way for the introduction of the private competitors in both generation and distribution of electric energy. However, the transmission system remains to be "inherent monopoly". in deregulated power systems, the transmission congestion occurs commonly and this leads to huge loss in revenue [5] [6] [7] [8]. The FACTS devices are being incorporated into the power system for capturing the unutilized potential of transmission systems. These FACTS [9] [10] [11] [12] devices are significant in controlling the operations of the power system and they can control the power flow by means of enhancing the transient stability margins. TCSC, which is a type of FACTS devices, can control the line impedance in a flexible manner with faster response. 
In general, the TCSC devices are constructed with a TCR linked in parallel with the capacitor. In electric power system, the TCSC is more commonly preferred for enhancing the capacities of transmission lines and for active power flow control [13] [14]. The optimal location and sizing of TCSC enhances the voltage profile and minimizes the power loss in the distribution system. The optimization algorithms play a key role in optimal placement and sizing of TCSC.

The major contribution of this research work is described below:

$\checkmark$ To achieve the optimal placement of TCSC, the objectives such as, "minimizing the congestion, reducing the investment cost and increasing the transient stability" is considered.

$\checkmark$ Introduces optimal placement and sizing with the aid of a meta-heuristic optimization algorithm referred as Modified Propagation Update Based WWO, which is the conceptual improvement of standard WWO algorithm.

The leftover sections are arranged as: Section 2 addresses the recent works undergone in TCSC placements. Section 3 tells about proposed optimal positioning of TCSC in power system. The resultant acquired with the optimization algorithms re discussed in Section 4. Finally, this paper is concluded in Section 5 .

\section{Literature Review}

\subsection{Related Works}

In 2020, Sayed et al. [1] have proposed an IMFO technique with the intention of optimally locating and sizing the TCSC in the power systems. The Multi-objective function like "minimization of loadability, load shedding, voltage stability index, and severity index" were solved for enhancing the loadability of the power system and for reducing the voltage collapse and load shedding. The authors have tested the proposed model in "standard IEEE-30 bus system".

In 2020, Sayed et al. [2] have comprehensively solved the TCSC allocation as well as steady-state load shedding problems in power system by the moth swarm algorithm. The emergency situations and the congestion were mitigated simultaneously. The "standard IEEE 30-bus test system" was utilized for testing the proposed model in terms of load shedding reduction, voltage profile improvements, active power loss minimization and voltage stability enhancement.

In 2020, Dash et al. [3] have proposed a novel hybrid algorithm referred as JMFO for reducing the transmission loss in the power system during the placement of the TCSC. The objective behind this research work was based on the reduction in the active power loss that had eventually paved way for the reduction in the installation cost of devices. They have tested the proposed work in "IEEE 14 bus and IEEE 30 bus systems".

In 2019, Jamnani and Pandya [4] have utilized a PSO for designing the coordinated parameters of TCSC and SVC. The authors have tested the proposed work with "IEEE-14 bus system" and have verified its efficiency in terms of "active power, reactive power (limit) and damping of oscillations".

In 2019, Sharma and Jain [5] have proposed a novel method for allocating TCSC on the basis of ATC and OPF, respectively. This allocation of TCSC was done using "congestion rent contribution approach" that was based on the location marginal price. In bilateral transactions environment, they have computed ATC using the "dc power transfer distribution factors ". In a pool electricity market, they have managed the congestion using the gravitational search assisted algorithm. The resultant of the proposed work was tested on "IEEE 30-bus and IEEE 57-bus test systems" in terms of congestion as well.

\section{Proposed Optimal Positioning of TCSC in Power System}

\subsection{Objective Function}

The overall objective of this research work is to optimally place the TCSC in the corresponding bus line for enhancing the power quality of the system. To achieve this, a multi-objective model that encloses three objectives like "minimization of congestion management Cost $_{\text {cong }}$, minimization of investment cost Cost $_{\text {invest }}$ and maximization of the transient stability $\mathrm{T}_{\text {stability }}$ are taken into consideration. Mathematically, the overall objective of this research work is given in Eq. (1).

$$
\text { Obj }=\operatorname{Min}\left[\text { Cost }_{\text {cong }}+\text { Cost }_{\text {invest }}+\frac{1}{\mathrm{~T}_{\text {stability }}}\right]
$$

Each of the objectives are discussed in the upcoming section. 
Investment Cost: The controlling of the power flow and the power system devices modelling in the modern power system can be solved with the investment cost minimization mechanism. Mathematically, the formulated investment cost with respect to system's operational range is expressed in Eq. (2). Here, Cost $_{\text {invest }}$ is the investment cost in $/ \mathrm{kVar}$ and $\mathrm{Instal}_{\mathrm{T}}$ is the TCSC installed capacity in MVar .

$$
\text { Cost }_{\text {invest }}=0.0015 . \text { Instal }_{\mathrm{T}}^{2}-0.713 \text { Instal }_{\mathrm{T}}+153.75
$$

Congestion management: In the deregulated environment, the issues regarding the security and reliability are solved by the congestion management. The mathematical formula for congestion management is expressed in Eq. (3), in which Power $_{n}$ is the Generation capacity parameter (in MW). In addition, Power $r_{n}$ can be expressed as per Eq. (4) and Eq. (5) respectively. In Eq. (5), $\Omega$ Power $_{n}$ is the produced power quantity.

$$
\begin{aligned}
\text { Cost }_{\text {cong }} & =\sum_{\mathrm{n}=1}^{\mathrm{N}_{\mathrm{g}}} \mathrm{f}\left(\Delta \text { Power }_{\mathrm{n}}\right) \\
\text { Power }_{\mathrm{n}}^{\text {min }} & \leq \text { Power }_{\mathrm{n}} \leq \text { Power }_{\mathrm{n}}^{\text {max }} \\
\text { Power }_{\mathrm{n}} & =\Omega \text { Power }_{\mathrm{n}}+\Delta \text { Power }_{\mathrm{n}}
\end{aligned}
$$

In addition, the Real power balance parameter Power $_{\text {real }}$ is considered, in which

$$
\sum_{n=1}^{N_{g}} \text { Power }_{n}-\left(\text { Power }_{\text {real }}+\text { Power }_{L}\right)=0
$$

And

$$
\begin{array}{r}
\text { Power }_{\mathrm{L}}=\sum_{\mathrm{m}=1 \mathrm{n}=1}^{\mathrm{N}_{\mathrm{g}}} \sum_{\mathrm{g}}^{\mathrm{N}_{\mathrm{g}}}\left(\text { Power }_{\mathrm{m}} \mathrm{A}_{\mathrm{mn}} \text { Power }_{\mathrm{n}}\right)+ \\
+\sum_{\mathrm{n}=1}^{\mathrm{N}_{\mathrm{g}}}\left(\mathrm{A}_{0 \mathrm{n}} \text { Power }_{\mathrm{n}}\right)+\mathrm{A}_{00}
\end{array}
$$

Here, transmission loss Power $_{\mathrm{L}}$ is mathematically expressed in Eq. (7), in which $\mathrm{A}_{\mathrm{mn}}, \mathrm{A}_{0 \mathrm{n}}$ and $\mathrm{A}_{00}$ indicates the loss coefficients.

Moreover, the stability limits guarantees the congestion issues and it is mathematically expressed as per Eq. (8), Eq. (9) and Eq. (10), respectively.

$$
\begin{gathered}
\operatorname{Vol}_{\mathrm{i}}^{\text {min }} \leq \mathrm{Vol}_{\mathrm{i}} \leq \mathrm{Vol}_{\mathrm{i}}^{\text {max }} \\
\varpi_{\mathrm{i}}^{\text {min }} \leq \varpi_{\mathrm{i}} \leq \varpi_{\mathrm{i}}^{\text {max }} \\
\text { Power }_{\mathrm{ij}}^{2}+\mathrm{Q}_{\mathrm{ij}}^{2} \leq\left(\text { Boun }_{\mathrm{ij}}^{\max }\right)^{2}
\end{gathered}
$$

In which $\left(\mathrm{Vol}_{i}^{\min }, \mathrm{Vol}_{i}^{\max }\right)$ are the voltage limits and $\left(\varpi_{i}^{\min }, \varpi_{i}^{\max }\right)$ are the angle limits. These voltage and angle limits describe the stability of the generators in terms of voltage in the load buses. In addition, Eq. (10) clearly shows no overloading of transmission lines takes place. The notation Boun ${ }_{\mathrm{ij}}{ }^{\max }$ (in MVA )is the boundary of maximum power flow.

Ramp up limits are said to be the quality limits corresponding to the "up and down rescheduling:" The mathematical formula for ramp limits are shown in Eq. (11).

$$
\Delta \text { Power }_{n}^{\min } \leq \Delta \text { Power }_{n} \leq \Delta \text { Power }_{n}^{\max }
$$

The congestion is reduced with optimal rescheduling approach using the minimum rescheduling cost.

Transient Stability: It is said to be the "ability of the power system to maintain synchronism, when subjected to a severe transient disturbance". The swing formulation aids in accomplishing the transient stability. In general, the swing formulation is non-linear and it cannot be solved with the systematic techniques. The numerical schemes are exploited with the intention solving the swing formulations. The Euler's method is adopted in this research work for solving the swing formulations.

Euler's approach: A "nonlinear differential formulation" is assumed in this research work and it is shown in Eq. (12).

$$
\frac{\mathrm{du}}{\mathrm{dtime}}=\text { fun }(\mathrm{u})
$$

In which, fun( $\mathrm{u})$ is the nonlinear function of $\mathrm{u}$.

The Eq. (12) is incorporated into the time moment $\left(\mathrm{time}_{0}, \mathrm{time}_{\text {fun }}\right)$ that has the "primary values as time $=$ time $_{0}$ and $u=u^{0}$ with a small time step $\Delta t$ ". This can be given as per Eq. (13).

$$
\mathrm{u}^{1}=\mathrm{u}^{0}+\left(\left.\frac{\mathrm{du}}{\operatorname{dtime}}\right|_{\mathrm{u}=\mathrm{u}^{0}}\right) \Delta \text { time }
$$


At time moment time $=$ time $_{0}+\Delta$ time, the parameter value is represented as $\mathrm{u}^{1}$ and this mechanism

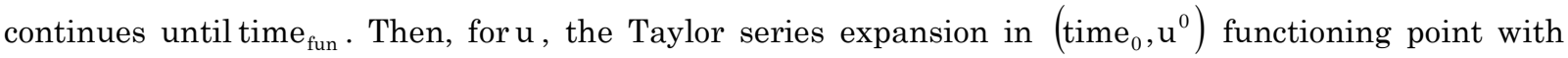
higher order variables can be discarded. Owing to the reduction in the higher variables, the errors might get crept into the system; therefore the Euler's scheme is updated with two phases: "(i) the corrector phase and (ii) the predictor phase". The corrector phase is mathematically expressed as per Eq. (14). In addition, the predictor phase is expressed as per Eq. (15).

$$
\begin{aligned}
& \mathrm{u}_{\mathrm{p}}^{\mathrm{k}+1}=\mathrm{u}^{\mathrm{k}}+\left(\left.\frac{\mathrm{du}}{\text { dtime }}\right|_{\mathrm{u}=\mathrm{u}^{\mathrm{k}}}\right) \Delta \text { time } \\
& \mathrm{u}_{\mathrm{c}}^{\mathrm{k}+1}=\mathrm{u}^{\mathrm{k}}+\frac{1}{2}\left(\left.\frac{\mathrm{du}}{\text { dtime }}\right|_{\mathrm{u}=\mathrm{u}_{\mathrm{p}}^{\mathrm{k}+1}}+\left.\frac{\mathrm{du}}{\text { dtime }}\right|_{\mathrm{u}=\mathrm{u}^{\mathrm{k}}}\right) \Delta \text { time }
\end{aligned}
$$

Here, the selection of $\Delta$ t (time step) need to be made with higher cautions as they may affect the accuracy of the system. Ideally, the value of (time step) is closer to zero. The trade-off between the step count and the accurateness need to be balanced. Therefore, the "second order differential formulations of the Single Machine Infinite Bus (SMIB) scheme" is implied in this research work. The mathematical formula for 2nd differential formulations of the SMIB scheme is shown in Eq. (16) and Eq. (17), respectively.

$$
\begin{aligned}
& \frac{\mathrm{d} \varphi}{\text { dtime }}=\rho-\rho_{\mathrm{s}}=\Delta \rho \\
& \frac{\mathrm{d} \Delta \rho}{\text { dtime }}=\frac{\pi \cdot \text { fun }_{\mathrm{s}}}{\mathrm{J}}\left(\text { Power }_{\mathrm{m}}-\text { Power }_{\max } \sin \varphi\right)
\end{aligned}
$$

Here, the mechanical power is denoted as Power $_{\mathrm{m}}$ and the transferred maximum power is specified as Power $_{\max }$. In addition, $\Delta \rho=\rho-\rho_{\mathrm{s}}$ specified the "variation of the rotor speed from the synchronous speed". For the Euler's technique, the predictor step is specified as per Eq. (18), Eq. (19) and Eq. (20), respectively.

$$
\begin{aligned}
& \varphi_{\mathrm{p}}^{\mathrm{k}+1}=\varphi^{\mathrm{k}}+\left.\frac{\mathrm{d} \varphi}{\operatorname{dtime}}\right|_{\substack{\varphi=\varphi^{\mathrm{k}} \\
\Delta \rho=\Delta \rho^{\mathrm{k}}}} \Delta \text { time } \\
& \Delta \rho_{\mathrm{p}}^{\mathrm{k}+1}=\Delta \rho^{\mathrm{k}}+\left.\frac{\mathrm{d} \Delta \rho_{\mathrm{me}}}{\text { dtime }}\right|_{\substack{\varphi=\varphi^{\mathrm{k}} \\
\Delta \rho=\Delta \rho^{\mathrm{k}}}} \Delta \text { time }
\end{aligned}
$$

The transient stability cost is mathematically expressed in Eq. (20).

$$
\mathrm{T}_{\text {stability }}=\text { Steady state response }\left(\Delta \rho_{\text {power }}^{\mathrm{k}+1}\right)
$$

\subsection{Solution Encoding}

The intended objectives (i.e., the "minimization of congestion management, the increase in transient stability and the reduction in investment cost") are reached by means of feeding the "positions and the sizing" of the TCSC as the input to the optimization algorithm. In this research work, the proposed optimal placement of TCSC is accomplished by implementing the proposed model in the "IEEE 24 bus system and the IEEE 9 bus systems". The Solution encoding of MPU-WWO is shown in Fig.1.

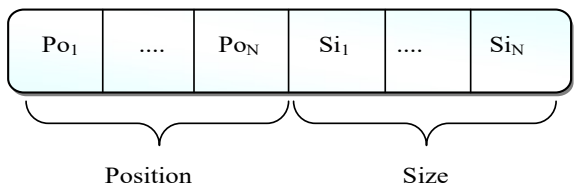

Fig. 1. Solution Encoding

Here, $\mathrm{Po}_{\mathrm{k}}$ indicates the position of TCSC in the bus line and $\mathrm{Si}_{\mathrm{k}}$ is the size of the TCSC controller for compensation. "Here, $\mathrm{k}=1,2,3 . . \mathrm{N}$ where, $\mathrm{N}=24$ and $\mathrm{N}=9$ for the IEEE 24 bus system and the IEEE 9 bus systems, respectively". The solution fed as input to the MPU-WWO Algorithm is shown in Fig. 1.

\subsection{MPU-WWO}

The MPU-WWO is the conceptual improvement of standard WWO algorithm. In general, WWO is based on the shallow water wave that is good in solving the complex optimization problems. Improved algorithms typically have non-convex and highly nonlinear solution spaces, and which are otherwise 
computationally difficult to solve by conventional mathematical programming methods. The steps followed in the MPU-WWO [15] is described in the upcoming section

Step 1: Population initialization of search agents corresponding to $\mathrm{S}$ of $\mathrm{w}$ waves

Step 2: check for the termination criteria, if not satisfied then proceed to step 3

Step 3: For each $\mathrm{S}$ waves, generates new wave $\mathrm{r}^{\prime}$ with propagation mechanism. The mathematical formula for propagation mechanism is shown in Eq. (21), in which random $[-1,1]$ is the arbitrary number garneted within the limit $(-1,1)$ and length of dimension $(\operatorname{dim})$ is Length(dim).

$$
\mathrm{S}^{\prime}(\operatorname{dim})=\mathrm{S}(\operatorname{dim})+\operatorname{random}[-1,1] \cdot \lambda \operatorname{Length}(\operatorname{dim})
$$

In addition, Length(dim)is determined using Eq. (22), in which $\mathrm{S}^{*}(\operatorname{dim})$ is the best solution of length.

$$
\mathrm{LE}=\mathrm{S}^{*}(\operatorname{dim})-\mathrm{S}(\operatorname{dim})
$$

Step 4: $\mathrm{F}\left(\mathrm{S}^{\prime}\right)>\mathrm{F}(\mathrm{S})$ and if $\mathrm{F}\left(\mathrm{S}^{\prime}\right)>\mathrm{F}\left(\mathrm{S}^{*}\right)$, then break $\mathrm{S}^{\prime}$ using Eq. (23).

$$
\mathbf{S}^{\prime}(\operatorname{dim})=\mathrm{S}(\operatorname{dim})+\mathrm{GN}(0,1) \cdot \beta \cdot \text { Length }(\operatorname{dim})
$$

Here, GN $(0,1)$ is the Gaussian random number with standard deviation $\sigma=1$ and mean $\mu=0$

Step 5: then, Update $S^{*}$ with $S^{\prime}$ and Substitute $S$ with $S^{\prime}$

Step 6: If $F\left(S^{\prime}\right) \leq F(S)$ and if $F\left(S^{\prime}\right) \leq F\left(S^{*}\right)$, then Reduce $S \cdot H$ by one. Height of wave is $H$

Step 7: if $\mathrm{r} \cdot \mathrm{H}=0$, then refract $\mathrm{S}$ to $\mathrm{S}^{\prime}$ using Eq. (24) and Eq. (25), respectively. The wavelength of wave is denoting as $\lambda$ and it is fixed as 0.5 . In addition, $\mathrm{Opt}_{\max }$ and $\mathrm{Opt}_{\min }$ is the maximum and minimum fitness value of the current iteration.

$$
\begin{aligned}
& \mathrm{S}^{\prime}(\operatorname{dim})=\mathrm{GN}\left(\frac{\mathrm{S} *(\operatorname{dim})+\mathrm{S}(\operatorname{dim})}{2}, \frac{|\mathrm{S} *(\operatorname{dim})-\mathrm{S}(\operatorname{dim})|}{2}\right) \\
& \lambda^{\prime}=\lambda \frac{\mathrm{Opt}(\mathrm{S})}{\operatorname{Opt}\left(\mathrm{S}^{\prime}\right)}
\end{aligned}
$$

Step 8: Update the wavelength using Eq. (26).

$$
\lambda=\lambda \cdot \alpha^{-\left(\mathrm{Opt}(\mathrm{S})-\mathrm{Opt}_{\min }+\varepsilon\right) /\left(\mathrm{Opt}_{\max }-\mathrm{Opt}_{\min }+\varepsilon\right)}
$$

Step 9: return $S^{*}$ and terminate the process.

\section{Results And Discussion}

\subsection{Simulation Procedure}

The proposed work with MPU-WWO based optimal placement of TCSC in the power system is implemented in MATLAB and the corresponding outcomes acquired are noted. In this research work, the simulation is accomplished with "IEEE 24 test bus system and the IEEE 9 test bus system". The loading of both "IEEE 24 test bus system and the IEEE 9 test bus system" is fixed at 150\%. The investment cost analysis and Congestion Cost are made for the proposed MPU-WWO model over the existing models like PSO based optimal placement, ABC based optimal placement, GWO based optimal placement, DA based optimal placement and WOA based optimal placement.

\subsection{Analysis on Investment Cost}

The Investment cost evaluation is made for the proposed work with MPU-WWO based optimal placement of TCSC as well as with the PSO [16], ABC [17], GWO [18], DA [19] and WOA [20] based optimal placement of TCSC in the power system. The result acquired from IEEE-24 and IEEE-9 bus system in terms of Investment cost is shown in Fig. 2(a) and Fig. 2(b), respectively. In IEEE-24 bus system, the investment cost for optimal placement of TCSC in the power system is lower, when compared to the existing models like the PSO based optimal placement, ABC based optimal placement, GWO based optimal placement, DA based optimal placement and WOA based optimal placement. The lowest investment cost 320 (\$) is recorded by the proposed work with MPU-WWO based optimal placement of TCSC for count of TCSC=2. In addition, the lowest investment cost of 350(\$) is recorded by the proposed work with MPU-WWO based optimal placement of TCSC, while the proposed work with PSO, ABC, GWO, DA and WOA achieves the highest investment cost as 376.35(\$), 378(\$), 376.35(\$), 376(\$) and $375(\$)$, respectively. Thus, from the evaluation, it is clear that the proposed work with MPU-WWO is good for optimal placement of TCSC. In addition, the optimal solutions acquired by the proposed work 
with MPU-WWO based optimal placement of TCSC and PSO, ABC, GWO, DA and WOA based optimal placement of TCSC in IEEE-24 and IEEE-9 bus system in Table 1 and Table 2, respectively.

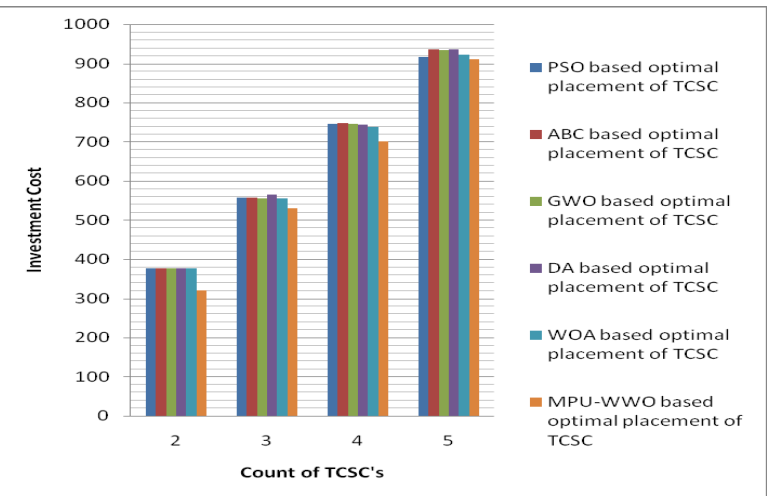

(a)

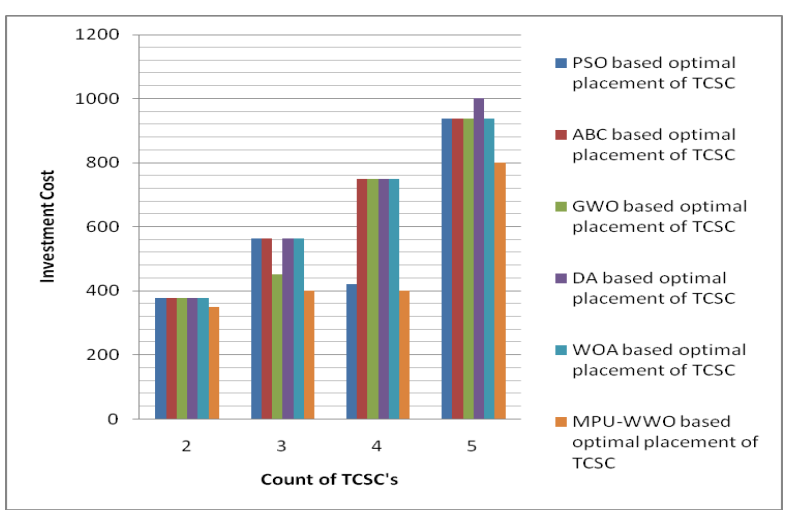

(b)

Fig. 2. Analysis on Investment cost of the proposed optimal placement and sizing of TCSC with diverse Metaheuristic Algorithms (a)IEEE-24 and IEEE-9 bus system

Table 1. Optimal Solutions Acquired By The Proposed Work With Diverse Meta-Heuristic Algorithms For IEEE-24 Bus System

\begin{tabular}{|c|c|c|c|c|c|c|c|c|c|c|c|c|}
\hline \multirow{3}{*}{\begin{tabular}{|l} 
Factors \\
\end{tabular}} & \multicolumn{12}{|c|}{ Count of TCSC $=2$} \\
\hline & \multicolumn{2}{|c|}{$\begin{array}{l}\text { PSO based } \\
\text { optimal } \\
\text { placement of } \\
\text { TCSC }\end{array}$} & \multicolumn{2}{|c|}{$\begin{array}{l}\text { ABC based } \\
\text { optimal } \\
\text { placement of } \\
\text { TCSC }\end{array}$} & \multicolumn{2}{|c|}{$\begin{array}{l}\text { GWO based } \\
\text { optimal } \\
\text { placement of } \\
\text { TCSC }\end{array}$} & \multicolumn{2}{|c|}{$\begin{array}{l}\text { DA based } \\
\text { optimal } \\
\text { placement of } \\
\text { TCSC }\end{array}$} & \multicolumn{2}{|c|}{$\begin{array}{l}\text { WOA based } \\
\text { optimal } \\
\text { placement of } \\
\text { TCSC }\end{array}$} & \multicolumn{2}{|c|}{$\begin{array}{l}\text { MPU-WWO based } \\
\text { optimal } \\
\text { placement of } \\
\text { TCSC }\end{array}$} \\
\hline & From & To & From & To & From & To & From & To & From & To & From & To \\
\hline \multirow[t]{2}{*}{ Position } & 4 & 9 & 13 & 23 & 13 & 23 & 1 & 2 & 11 & 14 & 11 & 14 \\
\hline & 10 & 12 & 9 & 12 & 21 & 22 & 1 & 3 & 9 & 12 & 1 & 2 \\
\hline \multirow{2}{*}{ Compensatior } & \multicolumn{2}{|c|}{-0.00795} & \multicolumn{2}{|c|}{-0.07856} & \multicolumn{2}{|c|}{-0.0895} & \multicolumn{2}{|c|}{-0.04766} & \multicolumn{2}{|c|}{-0.04305} & \multicolumn{2}{|c|}{-0.07856} \\
\hline & \multicolumn{2}{|c|}{-0.09759} & \multicolumn{2}{|c|}{-0.05987} & \multicolumn{2}{|c|}{0.18454} & \multicolumn{2}{|c|}{-0.40262} & \multicolumn{2}{|l|}{0.7} & \multicolumn{2}{|l|}{0.7} \\
\hline \multirow{3}{*}{ Factors } & \multicolumn{12}{|c|}{ Count of TCSC $=3$} \\
\hline & \multicolumn{2}{|c|}{$\begin{array}{l}\text { PSO based } \\
\text { optimal } \\
\text { placement of } \\
\text { TCSC } \\
\end{array}$} & \multicolumn{2}{|c|}{$\begin{array}{l}\text { ABC based } \\
\text { optimal } \\
\text { placement of } \\
\text { TCSC } \\
\end{array}$} & $\begin{array}{l}\text { GWO } \\
\text { optin } \\
\text { place } \\
\text { TCSC }\end{array}$ & of & $\begin{array}{l}\text { DA b } \\
\text { optin } \\
\text { place } \\
\text { TCSC }\end{array}$ & & $\begin{array}{l}\text { WOA } \\
\text { optin } \\
\text { place } \\
\text { TCSC }\end{array}$ & & $\begin{array}{l}\text { MPU } \\
\text { optin } \\
\text { place } \\
\text { TCS }\end{array}$ & $\begin{array}{l}\text { based } \\
\text { of }\end{array}$ \\
\hline & From & To & From & To & From & To & From & To & From & To & From & To \\
\hline & 3 & 9 & 10 & 12 & 21 & 22 & 1 & 2 & 10 & 11 & 15 & 21 \\
\hline Position & 17 & 18 & 8 & 9 & 16 & 19 & 1 & 3 & 9 & 11 & 11 & 14 \\
\hline & 15 & 24 & 16 & 17 & 18 & 21 & 1 & 5 & 21 & 22 & 21 & 22 \\
\hline & $-0.00^{\prime}$ & & -0.047 & & $-0.00^{\prime}$ & & -0.699 & & 0.236 & & $-0.00^{\prime}$ & \\
\hline Compensation & -0.04 & & -0.123 & & -0.04 & & -0.18 & & 0.234 & & 0.7 & \\
\hline & 0.116 & & -0.187 & & 0.546 & & -0.22 & & -0.18 & & 0.109 & \\
\hline & & & & & & 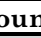 & f TC & & & & & \\
\hline Factors & $\begin{array}{l}\text { PSO } \\
\text { optin } \\
\text { place } \\
\text { TCS }\end{array}$ & & $\begin{array}{l}\text { ABC } \\
\text { optin } \\
\text { place } \\
\text { TCSC }\end{array}$ & & $\begin{array}{l}\text { GWO } \\
\text { optin } \\
\text { place } \\
\text { TCSC }\end{array}$ & & $\begin{array}{l}\text { DA b } \\
\text { optin } \\
\text { place } \\
\text { TCSC }\end{array}$ & & $\begin{array}{l}\text { WOA } \\
\text { optin } \\
\text { place } \\
\text { TCSC }\end{array}$ & & $\begin{array}{l}\text { MPU } \\
\text { optin } \\
\text { place } \\
\text { TCS }\end{array}$ & based \\
\hline & From & To & From & To & From & To & From & To & From & To & From & To \\
\hline & 13 & 23 & 7 & 8 & 1 & 2 & 11 & 13 & 19 & 20 & 12 & 13 \\
\hline Position & 8 & 10 & 5 & 10 & 15 & 21 & 21 & 22 & 15 & 21 & 21 & 22 \\
\hline & 12 & 23 & 1 & 2 & 7 & 8 & 19 & 20 & 16 & 17 & 19 & 20 \\
\hline & 3 & 24 & 10 & 11 & 11 & 13 & 1 & 2 & 16 & 19 & 12 & 23 \\
\hline & 0.664 & & 0.046 & & 0.030 & & -0.039 & & 0.354 & & 0.043 & \\
\hline IC & 0.354 & & -0.328 & & 0.354 & & 0.7 & & 0.391 & & 0.354 & \\
\hline Jompensation & -0.15 & & 0.046 & & 0.428 & & 0.046 & & 0.046 & & 0.118 & \\
\hline & 0.530 & & 0.127 & & 0.354 & & 0.293 & & -0.10 & & 0.046 & \\
\hline & & & & & & ou & f TCS & & & & & \\
\hline Factors & $\begin{array}{l}\text { PSO } \\
\text { optin } \\
\text { place } \\
\text { TCSC } \\
\end{array}$ & & $\begin{array}{l}\text { ABC } \\
\text { optin } \\
\text { place } \\
\text { TCSC }\end{array}$ & & $\begin{array}{l}\text { GWO } \\
\text { optin } \\
\text { place } \\
\text { TCSC }\end{array}$ & & $\begin{array}{l}\text { DA b } \\
\text { optin } \\
\text { place } \\
\text { TCSC }\end{array}$ & & $\begin{array}{l}\text { WOA } \\
\text { optin } \\
\text { place } \\
\text { TCSC }\end{array}$ & & $\begin{array}{l}\text { MPU } \\
\text { optin } \\
\text { place } \\
\text { TCS }\end{array}$ & $\begin{array}{l}\text { based } \\
\text { of }\end{array}$ \\
\hline & From & To & From & To & From & To & From & To & From & To & From & To \\
\hline & 15 & 21 & 9 & 11 & 1 & 2 & 3 & 9 & 12 & 23 & 19 & 20 \\
\hline Position & 16 & 19 & 3 & 24 & 21 & 22 & 3 & 24 & 1 & 5 & 18 & 21 \\
\hline & 15 & 21 & 1 & 3 & 1 & 3 & 9 & 12 & 4 & 9 & 16 & 19 \\
\hline
\end{tabular}




\begin{tabular}{|l|l|l|l|l|l|l|l|l|l|l|l|l|}
\hline & 18 & 21 & 10 & 11 & 11 & 14 & 1 & 5 & 21 & 22 & 21 & 22 \\
\cline { 2 - 9 } & 18 & 21 & 1 & 2 & 2 & 4 & 1 & 3 & 15 & 24 & 15 & 21 \\
\hline \multirow{5}{*}{ Compensation } & -0.03781 & 0.35403 & -0.04704 & -0.02152 & -0.02281 & 0.084866 \\
\cline { 2 - 9 } & 0.043081 & 0.043081 & -0.11044 & -0.17786 & 0.046497 & 0.7 \\
\cline { 2 - 9 } & 0.27261 & 0.027952 & -0.175 & 0.33421 & 0.12183 & 0.7 \\
\cline { 2 - 9 } \\
\cline { 2 - 9 } & 0.46599 & 0.27261 & 0.12495 & 0.27261 & 0.66439 & 0.27261 \\
\hline
\end{tabular}

Table 2. Optimal Solutions Acquired By The Proposed Work With Diverse Meta-Heuristic Algorithms For IEEE-9 Bus System

\begin{tabular}{|c|c|c|c|c|c|c|c|c|c|c|c|c|}
\hline \multirow{3}{*}{ Factors } & \multicolumn{12}{|c|}{ For 2 TCSC } \\
\hline & \multicolumn{2}{|c|}{$\begin{array}{l}\text { PSO based } \\
\text { optimal } \\
\text { placement of } \\
\text { TCSC } \\
\end{array}$} & \multicolumn{2}{|c|}{$\begin{array}{l}\text { ABC based } \\
\text { optimal } \\
\text { placement of } \\
\text { TCSC }\end{array}$} & \multicolumn{2}{|c|}{$\begin{array}{l}\text { GWO based } \\
\text { optimal } \\
\text { placement of } \\
\text { TCSC }\end{array}$} & \multicolumn{2}{|c|}{$\begin{array}{l}\text { DA based } \\
\text { optimal } \\
\text { placement of } \\
\text { TCSC } \\
\end{array}$} & \multicolumn{2}{|c|}{$\begin{array}{l}\text { WOA based } \\
\text { optimal } \\
\text { placement of } \\
\text { TCSC }\end{array}$} & \multicolumn{2}{|c|}{$\begin{array}{l}\text { MPU-WWO based } \\
\text { optimal } \\
\text { placement of } \\
\text { TCSC }\end{array}$} \\
\hline & From & To & From & To & From & To & From & To & From & To & From & To \\
\hline \multirow{2}{*}{ Position } & 8 & 2 & 8 & 9 & 5 & 6 & 7 & 8 & 6 & 7 & 4 & 5 \\
\hline & 8 & 9 & 6 & 7 & 6 & 7 & 9 & 4 & 5 & 6 & 1 & 4 \\
\hline \multirow{2}{*}{ Compensation } & \multicolumn{2}{|l|}{0.17} & \multicolumn{2}{|c|}{0.009669} & \multicolumn{2}{|l|}{0.17} & \multicolumn{2}{|c|}{0.12959} & \multicolumn{2}{|l|}{0.17} & \multicolumn{2}{|c|}{-0.01425} \\
\hline & \multicolumn{2}{|c|}{-0.06684} & \multicolumn{2}{|c|}{0.045408} & \multicolumn{2}{|c|}{-0.02727} & \multicolumn{2}{|c|}{0.030427} & \multicolumn{2}{|c|}{-0.02727} & \multicolumn{2}{|c|}{0.030427} \\
\hline \multirow{3}{*}{ Factors } & & & & & & & 3 TCS & & & & & \\
\hline & $\begin{array}{l}\text { PSO b } \\
\text { optim } \\
\text { placer } \\
\text { TCSC }\end{array}$ & & $\begin{array}{l}\text { ABC } \\
\text { optim } \\
\text { place } \\
\text { TCSC }\end{array}$ & & $\begin{array}{l}\text { GWO } \\
\text { optim } \\
\text { place } \\
\text { TCSC }\end{array}$ & & $\begin{array}{l}\text { DA b: } \\
\text { optim } \\
\text { place } \\
\text { TCSC }\end{array}$ & & $\begin{array}{l}\text { WOA 1 } \\
\text { optim } \\
\text { placen } \\
\text { TCSC }\end{array}$ & & $\begin{array}{l}\text { MPU } \\
\text { optin } \\
\text { place } \\
\text { TCSC }\end{array}$ & $\begin{array}{l}\text { based } \\
\text { of }\end{array}$ \\
\hline & From & To & From & To & From & To & From & To & From & To & From & To \\
\hline & 8 & 2 & 5 & 6 & 5 & 6 & 5 & 6 & 6 & 7 & 4 & 5 \\
\hline Position & 8 & 9 & 6 & 7 & 6 & 7 & 6 & 7 & 5 & 6 & 1 & 4 \\
\hline & 6 & 7 & 9 & 4 & 6 & 7 & 9 & 4 & 6 & 7 & 9 & 4 \\
\hline & 0.17 & & 0.145 & & -0.027 & & 0.17 & & 0.17 & & -0.014 & \\
\hline Compensation & 0.17 & & 0.0096 & & 0.0454 & & 0.071 & & -0.0668 & & 0.030 & \\
\hline & -0.0668 & & 0.058 & & 0.17 & & 0.081 & & 0.1295 & & 0.071 & \\
\hline & & & & & & & 4 TCSS & & & & & \\
\hline Factors & $\begin{array}{l}\text { PSO b } \\
\text { optim } \\
\text { placer } \\
\text { TCSC } \\
\end{array}$ & & $\begin{array}{l}\text { ABC } \\
\text { optim } \\
\text { place } \\
\text { TCSC } \\
\end{array}$ & & \begin{tabular}{|l|} 
GWO \\
optim \\
place \\
TCSC \\
\end{tabular} & & $\begin{array}{l}\text { DA b: } \\
\text { optim } \\
\text { place } \\
\text { TCSC }\end{array}$ & & $\begin{array}{l}\text { WOA 1 } \\
\text { optim } \\
\text { placen } \\
\text { TCSC }\end{array}$ & & $\begin{array}{l}\text { MPU } \\
\text { optin } \\
\text { place } \\
\text { TCSC }\end{array}$ & based \\
\hline & From & To & From & To & From & To & From & To & From & To & From & To \\
\hline & 8 & 9 & 6 & 7 & 7 & 8 & 5 & 6 & 6 & 7 & 4 & 5 \\
\hline Position & 6 & 7 & 8 & 9 & 5 & 6 & 7 & 8 & 8 & 9 & 6 & 7 \\
\hline & 4 & 5 & 8 & 9 & 6 & 7 & 9 & 4 & 5 & 6 & 5 & 6 \\
\hline & 6 & 7 & 6 & 7 & 8 & 9 & 4 & 5 & 7 & 8 & 6 & 7 \\
\hline & 0.17 & & 0.045 & & 0.05 & & 0.016 & & -0.0 & & 0.0 & \\
\hline & -0.0668 & & 0.17 & & 0.0675 & & 0.074 & & 0.0 & & -0.064 & \\
\hline Con & 0.0602 & & 0.045 & & 0.0602 & & -0.013 & & 0.0454 & & 0.17 & \\
\hline & -0.17 & & 0.17 & & -0.17 & & 0.0748 & & 0.17 & & -0.17 & \\
\hline & & & & & & & $5 \mathrm{TCS}$ & & & & & \\
\hline Factors & $\begin{array}{l}\text { PSO b } \\
\text { optim } \\
\text { placer } \\
\text { TCSC }\end{array}$ & & $\begin{array}{l}\text { ABC } \\
\text { optim } \\
\text { place } \\
\text { TCSC } \\
\end{array}$ & & \begin{tabular}{|l|} 
GWO \\
optim \\
place \\
TCSC \\
\end{tabular} & & $\begin{array}{l}\text { DA b: } \\
\text { optim } \\
\text { place } \\
\text { TCSC }\end{array}$ & & $\begin{array}{l}\text { WOA 1 } \\
\text { optim } \\
\text { placen } \\
\text { TCSC }\end{array}$ & & $\begin{array}{l}\text { MPU } \\
\text { optin } \\
\text { place } \\
\text { TCSC }\end{array}$ & based \\
\hline & From & To & From & To & From & To & From & To & From & To & From & To \\
\hline & 8 & 9 & 8 & 9 & 8 & 9 & 4 & 5 & 7 & 8 & 5 & 6 \\
\hline & 4 & 5 & 6 & 7 & 1 & 4 & 7 & 8 & 5 & 6 & 6 & 7 \\
\hline Position & 6 & 7 & 5 & 6 & 5 & 6 & 5 & 6 & 6 & 7 & 7 & 8 \\
\hline & 5 & 6 & 6 & 7 & 6 & 7 & 6 & 7 & 1 & 4 & 5 & 6 \\
\hline & 8 & 2 & 8 & 9 & 4 & 5 & 8 & 9 & 5 & 6 & 6 & 7 \\
\hline & -0.075 & & -0.127 & & -0.013 & & $0.002 !$ & & 0.0454 & & -0.013 & \\
\hline & 0.0635 & & $0.002 s$ & & 0.0748 & & -0.064 & & 0.17 & & 0.074 & \\
\hline Compensation & -0.105 & & -0.064 & & 0.0493 & & -0.085 & & 0.0029 & & -0.064 & \\
\hline & 0.0029 & & -0.022 & & 0.0692 & & -0.075 & & -0.0646 & & -0.064 & \\
\hline & -0.0646 & & 0.050 & & 0.0391 & & 0.063 & & 0.17 & & 0.058 & \\
\hline
\end{tabular}

\subsection{Analysis on Congestion Cost}

The congestion cost evaluation for "IEEE-24 and IEEE-9 bus system" for the proposed TCSC optimal placement model with MPU-WWO, PSO, ABC, GWO, DA and WOA are shown in Fig.4 (a) and Fig. 4(b), 
respectively. The lowest congestion cost is recorded as 196(\$) by the proposed work with MPU-WWO, when the count of TCSC $=2$. In addition, when the count of TCSC=3, the lowest congestion cost is recorded as 500(\$) by the proposed work with MPU-WWO, while the proposed work with PSO, ABC, GWO, DA and WOA records the congestion cost as $530(\$), 510(\$), 555(\$), 510(\$)$ and $554.74(\$)$. In addition, the congestion cost of IEEE-9 bus system for the proposed TCSC based optimization position model is shown in Fig. 3(b). Here, the proposed TCSC based model with MPU-WWO achieves the lowest congestion cost, while compared to the other optimization models. The adopted TCSC optimal positioning scheme for 3 TCSCs is $8.02 \%, 12.17 \%, 20.5 \%, 6.7 \%$ and $10.4 \%$ superior to PSO based optimal placement, ABC based optimal placement, GWO based optimal placement, DA based optimal placement and WOA based optimal placement. Thus, from the overall evaluation, it is clear that the optimal placement of TCSC achieves the lowest congestion cost with MPU-WWO.

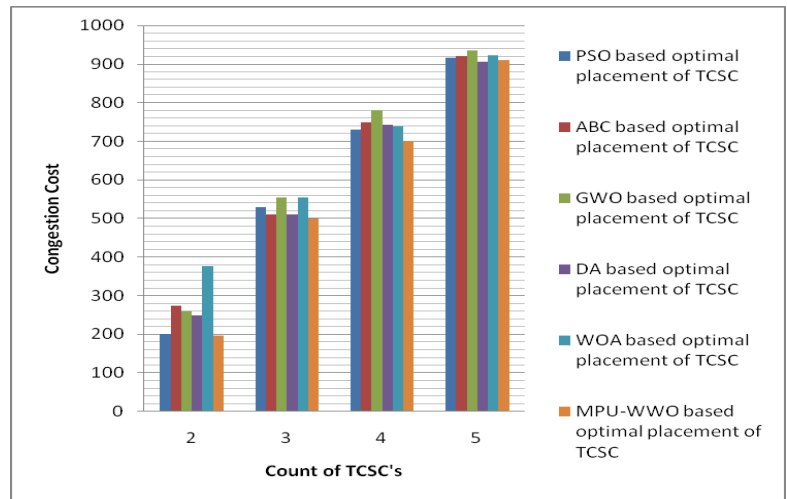

(a)

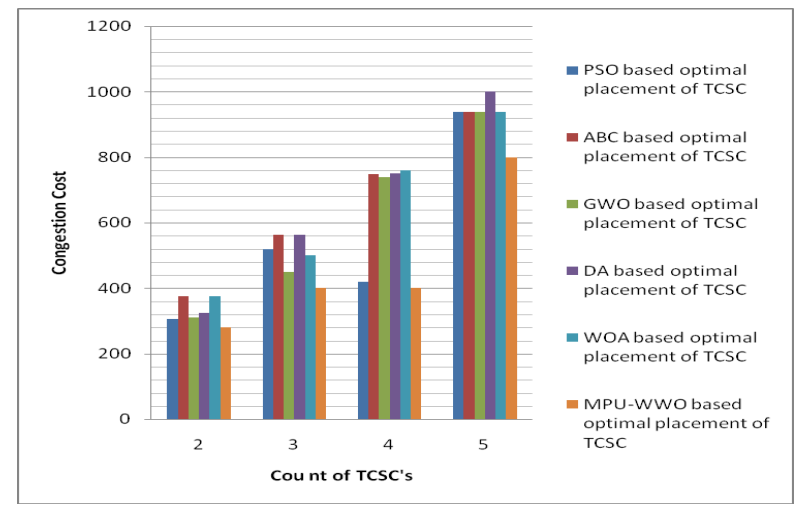

(b)

Fig. 3. Analysis on Congestion cost of the proposed optimal placement and sizing of TCSC with diverse Metaheuristic Algorithms (a)IEEE-24 and IEEE-9 bus system

\section{Conclusion}

An optimal placement and sizing of TCSC was developed in this research by means of considering the objectives such as, "minimizing the congestion, reducing the investment cost and increasing the transient stability". The optimal placement is done with the aid of a meta-heuristic optimization algorithm referred as MPU-WWO, which is the conceptual improvement of standard Water wave Optimization (WWO) algorithm. In this research work, the simulation was accomplished with "IEEE 24 test bus system and the IEEE 9 test bus system". The loading of both "IEEE 24 test bus system and the IEEE 9 test bus system" was fixed at $150 \%$. The investment cost analysis and Congestion Cost were made for the proposed MPU-WWO model over the existing models like PSO based optimal placement, ABC based optimal placement, GWO based optimal placement, DA based optimal placement and WOA based optimal placement. In addition, when the count of $\mathrm{TCSC}=3$, the lowest congestion cost is recorded as 500 (\$) by the proposed work with MPU-WWO, while the proposed work with PSO, ABC, GWO, DA and WOA records the congestion cost as $530(\$), 510(\$), 555(\$), 510(\$)$ and $554.74(\$)$.

\section{Compliance with Ethical Standards}

Conflicts of interest: Authors declared that they have no conflict of interest.

Human participants: The conducted research follows the ethical standards and the authors ensured that they have not conducted any studies with human participants or animals.

\section{References}

[1] Fatma Sayed, Salah Kamel, Mahrous Ahmed Taher \& Francisco Jurado,"Enhancing power system loadability and optimal load shedding based on TCSC allocation using improved moth flame optimization algorithm",Electrical Engineering,2020

[2] Fatma Sayed, Salah Kamel, Juan Yu \& Francisco Jurado,"Optimal Load Shedding of Power System Including Optimal TCSC Allocation Using Moth Swarm Algorithm",Iranian Journal of Science and Technology, Transactions of Electrical Engineering, Vol.44,pp.741-765,2020 
[3] Stita Pragnya Dash, K. R. Subhashini \& J. K. Satapathy ,"Optimal location and parametric settings of FACTS devices based on JAYA blended moth flame optimization for transmission loss minimization in power systems",Microsystem Technologies , Vol.26,pp.1543-1552,2020

[4] J.G.Jamnani and Maulikkumar Pandya,"Coordination of SVC and TCSC for Management of Power Flow by Particle Swarm Optimization",Energy Procedia,Vol.156,pp.321-326,2019

[5] Akanksha Sharma and Sanjay K.Jain,"Gravitational search assisted algorithm for TCSC placement for congestion control in deregulated power system",Electric Power Systems Research,Vol.174,2019

[6] P. K. Tiwari and Y. R. Sood, "An Efficient Approach for Optimal Allocation and Parameters Determination of TCSC With Investment Cost Recovery Under Competitive Power Market," in IEEE Transactions on Power Systems, vol. 28, no. 3, pp. 2475-2484, Aug. 2013.

[7] X. Xu, J. Zhao, Z. Xu, S. Chai, J. Li and Y. Yu, "Stochastic optimal TCSC placement in power system considering high wind power penetration," in IET Generation, Transmission \& Distribution, vol. 12, no. 12, pp. 3052-3060, 1072018

[8] M. Sahraei-Ardakani and Y. Sang, "Discussion on Linear Modeling of Variable Reactance in "Co-Optimization of Transmission Expansion Planning and TCSC Placement Considering the Correlation Between Wind and Demand Scenarios"," in IEEE Transactions on Power Systems, vol. 33, no. 5, pp. 5808-5809, Sept. 2018

[9] O. Ziaee, O. Alizadeh-Mousavi and F. F. Choobineh, "Co-Optimization of Transmission Expansion Planning and TCSC Placement Considering the Correlation Between Wind and Demand Scenarios," in IEEE Transactions on Power Systems, vol. 33, no. 1, pp. 206-215, Jan. 2018.

[10] E. Ghahremani and I. Kamwa, "Optimal placement of multiple-type FACTS devices to maximize power system loadability using a generic graphical user interface," IEEE Transactions on Power Systems, vol. 28, no. 2, pp. 764-778, May 2013.

[11] S. Mahapatra, A. N. Jha and B. K. Panigrahi, "Hybrid technique for optimal location and cost sizing of thyristor controlled series compensator to upgrade voltage stability," in IET Generation, Transmission \& Distribution, vol. 10, no. 8, pp. 1921-1927, 1952016.

[12] O. Ziaee and F. Choobineh, "Optimal Location-Allocation of TCSCs and Transmission Switch Placement Under High Penetration of Wind Power," IEEE Transactions on Power Systems, vol. 32, no. 4, pp. 3006-3014, July 2017.

[13] S. Dawn, P. Kumar Tiwari, A. Kumar Goswami and R. Panda, "An Approach for System Risk Assessment and Mitigation by Optimal Operation of Wind Farm and FACTS Devices in a Centralized Competitive Power Market," IEEE Transactions on Sustainable Energy, vol. 10, no. 3, pp. 1054-1065, July 2019.

[14] F. B. Alhasawi and J. V. Milanovic, "Techno-Economic Contribution of FACTS Devices to the Operation of Power Systems With High Level of Wind Power Integration," IEEE Transactions on Power Systems, vol. 27, no. 3, pp. 1414-1421, Aug. 2012

[15] Malige Gangappa, C. Kiran Mai, P. Sammula, "Classification of land cover images using modified water wave Optimization-based hybrid classifier",International Journal of Computers and Applications",2019

[16] M.R.Tanweer, S.Suresh, and N.Sundararajan, " Self regulating particle swarm optimization algorithm", Information Sciences, vol. 294, pp. 182-202, 2015.

[17] D.KarabogaB.Basturk, " On the performance of artificial bee colony (ABC) algorithm", Applied Soft Computing, vol. 8, no. 1, pp. 687-697, 2008.

[18] Seyedali Mirjalili, Seyed Mohammad Mirjalili, Andrew Lewis, "Grey Wolf Optimizer", Advances in Engineering Software, Vol.69, pp, 46-61, 2014.

[19] Seyedali Mirjalili,"Dragonfly algorithm: a new meta-heuristic optimization technique for solving single-objective, discrete, and multi-objective problems",Neural Computing and Applications, vol.27, no.4, pp 1053-1073, May 2016.

[20] Seyedali Mirjalili,Andrew Lewisa,"The Whale Optimization Algorithm",Advances in Engineering Software,vol.95,pp.51-67,May 2016. 